\title{
The Shielding of Inbound Radiofrequency Electromagnetic Fields at Workplaces
}

\author{
Tarmo Koppel, Tallinn University of Technology, Mikko Ahonen, University of Tampere
}

\begin{abstract}
The emergence of new technologies and increased use of wireless voice and data transmissions has increased the human exposure to the radiofrequency (RF) electromagnetic fields (EMFs). Effective reduction measures of these fields have become more relevant in risk management at workplaces. Not only occupational health, but also counter-espionage and low electromagnetic interference are important arguments for RF EMF mitigation. This study investigates the most commonly used mitigation materials and methods of RF EMFs. The materials investigated in this study included: a graphite based paint; a wire netting; a foil paper; a metalized fabric; a transparent conductive film and other solutions. The study undertook two kinds of measurements: 1) a semi-controlled environment was created to test the mitigation materials/methods under equal conditions, 2) measurements were conducted before and after the implementation of the intervention measures in the actual living and working environments. The results revealed great differences in various mitigation materials and methods: under semicontrolled conditions the best shielding capability was achieved by metallized fabric, followed by iron wire netting and foil paper. Iron bars produced moderate screening whereas graphite paint and metallic frame proved to have little effect.
\end{abstract}

Keywords: Electromagnetic fields, mitigation, radiofrequency, reduction, risk management, shielding.

\section{INTRODUCTION}

The widespread use of modern telecommunication technologies has increased the ambient radiofrequency electromagnetic fields in today's urban areas. Rural areas are not affected to the same extent, as scattered settlements require and produce less intense network of wireless communications.

The need to mitigate RF electromagnetic fields can be argued from multiple points of view: a need to protect sensitive electronic systems from electromagnetic interference (EMI), health risk management and counter-espionage purposes. In the market there are several products aimed to screen out or to absorb RF electromagnetic fields (EMFs) from outside (inbound) sources.

Many developments in the electronic industry and the expanded use of electronic devices in communications, automations, computations, biomedicine and for other purposes have raised many issues related to electromagnetic interference (EMI) [1]. Aniolczyk and Koprowska (2004) analyzed workplaces exposed to strong EMF and found out the need to lower the exposure in industry, medicine, radio communication and broadcasting in special conditions [2].

Strong electromagnetic fields may be encountered in a great number of industrial processes: radiofrequency welding, industrial microwave ovens, mobile communication masts, radar towers, high power transceivers and their antenna arrays, welding, induction heating and others. High exposure to the RF EMFs can be encountered by workers nearby plastic sealers and glue dryers. Radio/TV tower workers and radar operators and technicians may also encounter high-level power densities [3].

The current safety limits on radiofrequency electromagnetic fields are based on health effects induced by the thermal biological changes. If the RF EMF is intense enough, it will cause body tissue heating and this effect is intended to be prevented by the safety limits [4], [5].

Standards produced by ICNIRP are also the basis for the legally binding safety limits in the European Union [6], [7].

Although the health effects from RF EMFs below the current safety limits remain a controversial topic, several studies have been published on solutions how to reduce and mitigate the EMFs. Reducing electromagnetic fields to as low as reasonably possible is also the general principle behind the public and occupational health legislation in Europe. Therefore, if the electromagnetic fields at the workplace are in conformation with the safety limits, this does not mean that the employer's obligations end there. The employer is obligated to reduce the EMFs to the minimum [6]. Best practice defines "minimum" to "as low as reasonably possible". This does not mean that the employer should invest into mitigation methods and materials that exceed the company's financial capabilities, but follow exemplary practices that have been implemented by others. Often, companies may be reluctant to undertake EMF mitigation measures due to their high cost. In this study low cost shielding materials were also included for their RF EMF shielding effectiveness to be tested.

Besides using RF EMF shielding materials, there are also other ways to reduce the effect of EMFs at the workplace. One of the first things is to reduce the RF reflections in the room by removing large metal surfaces. All metal parts (e.g., construction elements, furniture such as metal cabinets) that the RF EMFs come to contact with can act as antennas or reflectors and, therefore, increase the levels of RF EMFs significantly. One of the problematic issues with the RF reflections is the so-called hot spots. These specific narrow locations may have a power density of hundred times greater than an area half a meter next to it. The occurrence of hot spots is directly dependent on the multiple reflections due to metal elements but also several signal sources that all happen to hit the same location. Therefore, a principle idea behind the mitigation measures is to minimize the usage of RF EMF sources indoors and to block inbound RF EMFs from 
neighborhood by shielding the walls, roofs, floors and windows with special materials.

Like metal items in the apartment or at the workplace, also metal in the human body will act as an antenna or a reflector and increase the levels of EMFs the person is exposed to. Such items may include: glasses with metal frame, metal jewelry, bras and even a simple thing as a zipper. In addition, metal in the human body - both active and passive medical implants may become risk factors in a high power density environment. Metallic knee implants and other metal in the body are common nowadays. Although the size of the implant determines the magnitude of the effect, dental implants, which are usually of a small size, will not play any significant role. Whereas a passive medical implant may become a risk factor if the EMF heats up the adjacent tissue, more concern has been shown in regard to active (electronic) medical implants. If the field is intense enough it may interfere with the operational activity of the implant, cause it to malfunction; as a result, injury or illness may follow [8]. Active medical implants are considered unaffected by typical EMF scenarios but may be vulnerable in industrial conditions where often high intensity electromagnetic fields are byproducts of production or other processes.

Although there are many materials developed for electromagnetic shielding, only a few of them are commonly used. Shielding materials are produced both by means of composition and method of production. Traditional shielding solutions use metallic (conductive) materials. Recently, conductive polymers have been introduced to replace metallic materials. In recent years, many new shielding materials have been tested: 1) polystyrene particles coated with copper by magnetron sputtering [9]; 2) polypropylene mixed glass fibers filled with copper wires [10]; 3) copper wire, polyamide filament, stainless steel wire [11]; 4) fly ash particulate produced aluminum matrix composites [12]; 5) copper wire and polyamide filaments wrapped with polypropylene filaments [13]; 6) multiwalled carbon nanotube filled polyacrylate composite films [14]; 7) glass fabric-epoxy composites containing conductive multi-walled carbon nanotubes [15]; 8) soft magnetic iron, aluminum, silicon alloy polymer composites [16]; 9) soft magnetic stainless steel fiber enabled polyester textiles [17], 10) polyaniline-coated transparent thin films [18], 11) carbon filling cement materials and metal filling cement composites [19].

Besides shielding working rooms, electromagnetic shielding is intensively used also in communications, aviation and military industries. Each of the branches has their own requirements for the shielding solutions. Aviation, for example, needs lightweight shielding materials and, therefore, requires carbon fiber filled with conductive elements [20].

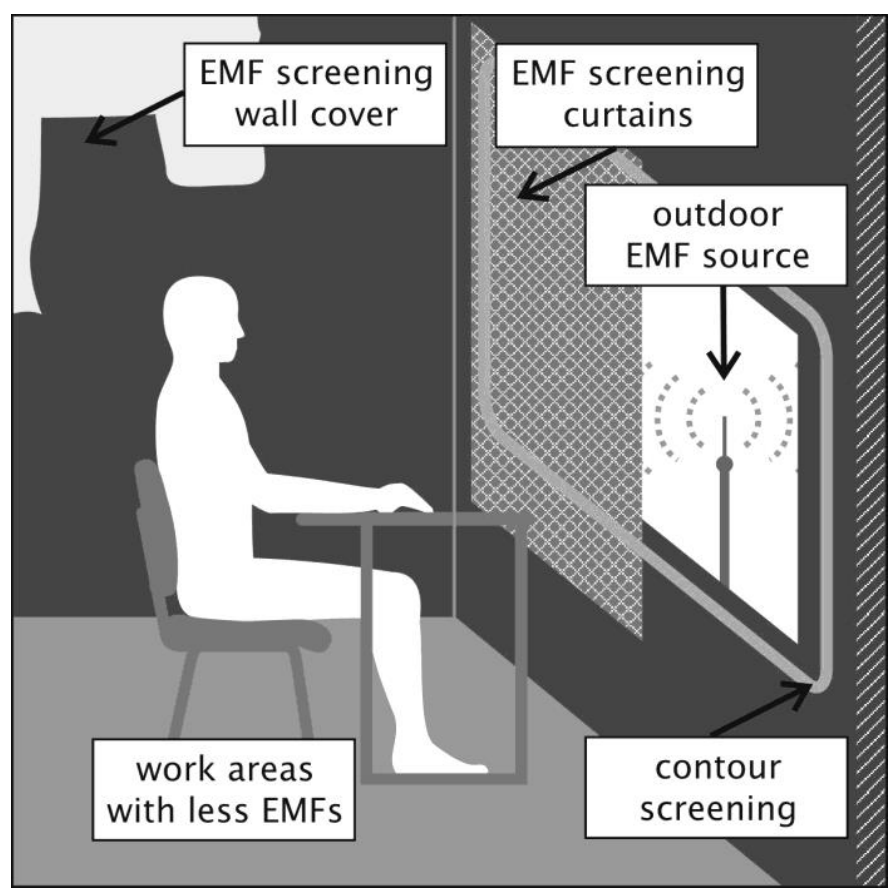

Fig. 1. Research context: the study investigated radiofrequency electromagnetic fields' mitigation effectiveness of various most commonly used screening materials

This study focuses on the EMFs that could penetrate through the walls and windows of the buildings. These are the EMFs generated outside the facilities of the observed person, i.e., those generated by mobile communication transmitters (mainly voice and data transmission).

The aim of this article is to test various materials/methods for shielding and reducing the radiofrequency (RF) electromagnetic fields (EMFs) suitable for office workplaces (Fig. 1). This paper points out the effective shielding measures, including both expensive and inexpensive alternatives. The literature does not provide many studies on comparing RF EMF mitigation measures, especially when it comes to the point of view of office workplaces.

The mitigation measures can be used for EMI, antiespionage and health risk management purposes. The importance of minimizing the exposure to the electromagnetic fields where possible is suggested also by high-level international and European bodies. Both business and private users are encouraged to avoid excessive exposure to the EMFs [21-24]. The research on the RF EMF effects on the health is still ongoing and new summary reports are published regularly [25-28]. Until the science is clearer in regard to the health effects, the precautionary principle is recommended, of which the mitigation procedures, including shielding, comprise a relevant part. 
Due to the previously mentioned "hot spots", assessment of personal exposure to the electromagnetic fields in real life scenarios can hardly be performed by a single measurement reading. Especially in case of the radiofrequency fields the distribution of the field strength levels can vary greatly across the worker's body. This can be demonstrated by a 14-point measurement map that covers the whole body [29].

As shown in Fig. 2, the radiofrequency field levels in an actual working environment can have a great variation across the worker's body. The presented picture represents inbound $\mathrm{RF}$ radiation entering the premises through the windows.

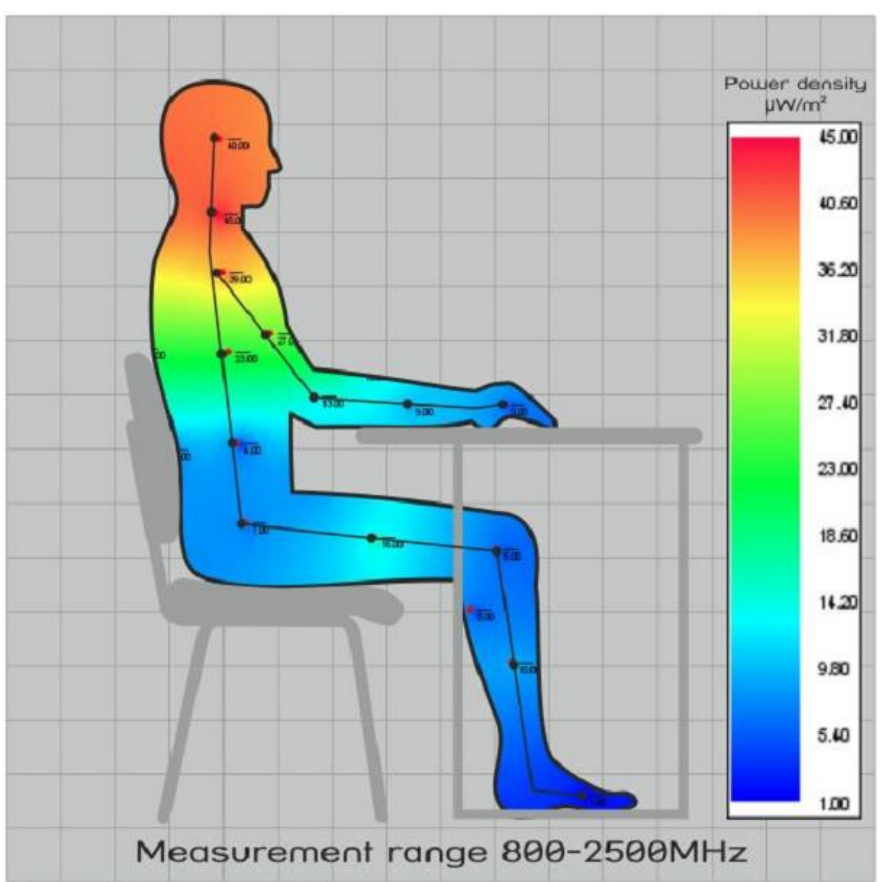

Fig. 2. RF EMF levels at worker's body, following a 14-point measurement model.

\section{METHOD}

The measurements were carried out in the RF range of the electromagnetic spectrum $(800-2500 \mathrm{MHz})$.

The measurements were conducted in two basic settings: 1) a semi-controlled environment with an actual mobile communication tower nearby and 2) an intervention procedure undertaken in an actual living or working environment.

The measurement instruments included the following:

- $\quad$ High frequency analyzer Gigahertz Solutions HF59B (Langenzenn, Germany) with directional

(HF800V2500LPE174) and omnidirectional (UBB27) antennas;

- $\quad$ Spectrum analyzer Aaronia Spectran HF6080 with a directional antenna HF6040;

- Data acquisition card;

- Laptop computer to record time series measurements and capture spectral recordings.
The measurements were taken in RMS mode (root mean square) of the high frequency analyzer. The meter is also specialized to detect short pulsed mode data transmissions, which makes it also suitable for the measurements undertaken in this study, since most modern wireless data is transmitted in that mode whereas other meters might miss or devaluate such data bursts.

The shielding effectiveness was assessed based on the reduced field intensity levels by each of the material/method investigated.

\section{A. Measurements under Semi-controlled Conditions}

The first measurement procedure was classified as semicontrolled, since the measurement was done in the vicinity of an actual mobile communication mast, the field levels of which were quite steady (approximately $1 \mathrm{~mW} / \mathrm{m}^{2}$ ) but uncontrolled by the researchers. Therefore, testing mitigation materials were preceded and followed by the measurements of ambient field levels to ensure that all the mitigation materials were analyzed under the same conditions.

A wooden frame of $1 \times 1.4 \times 1 \mathrm{~m}$ (width, height, depth) was built to accommodate the mitigation materials. The location for the test frame was selected where the following criteria were met: 1) the ambient field levels were stable, 2) the RF radiation came mainly from one direction, i.e., had a direct line of view to the mast (Fig. 6) and 3) the measurement location was not significantly affected by secondary RF radiation by reflection. The measurement location was outside the residential area to give a close approximation of the actual conditions where the shielding materials were likely to be used. The material under testing was placed at a distance of $15 \mathrm{~cm}$ from the measurement antenna in the direction of the mobile communications mast (Fig. 3).

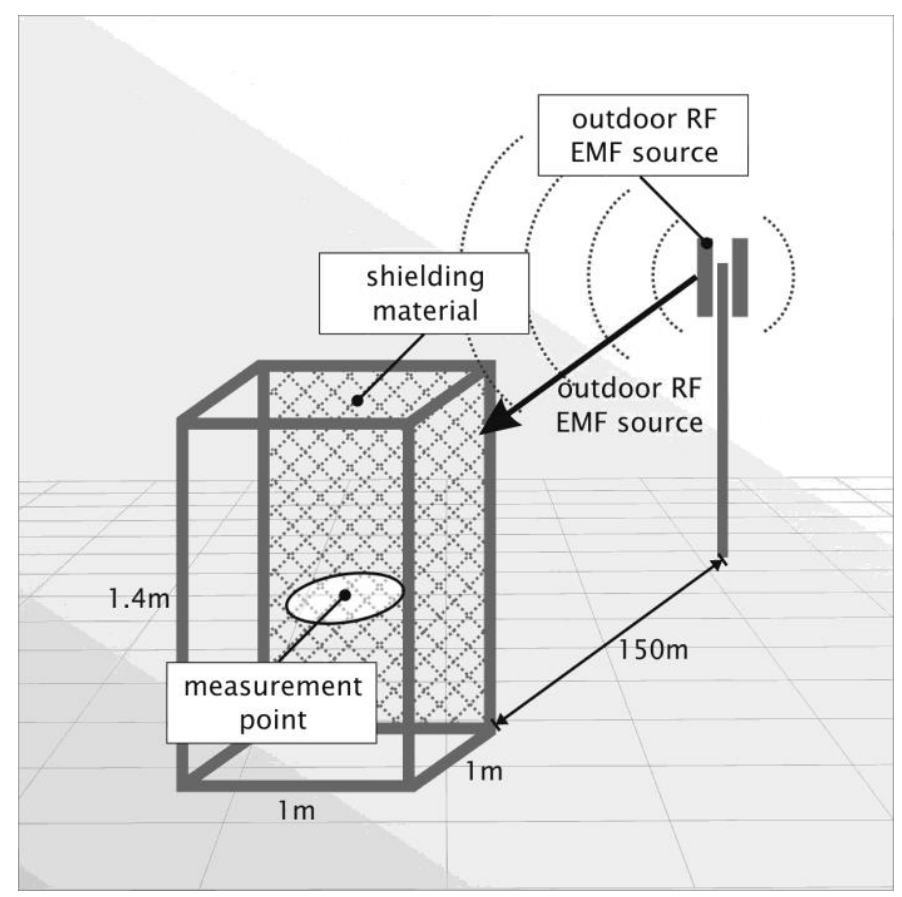

Fig. 3. The set-up for semi-controlled condition measurements. 
In order to minimize sudden fluctuations in time series, each material under testing was measured for the period of two minutes, the data logging system recorded the field intensity level - 2 samples per second. Therefore, each recording consisted of about 240 samples, of which the minimum, maximum, average and median values were calculated.

The reduction factor of the material tested was analyzed in comparison with the "plain frame" setting where the measurement booth had no obstacles between the HF analyzer and the radiation source. Based on these two readings, a reduction factor was calculated in the logarithmic scale (in $\mathrm{dB}$ ) (formula 1), where $\mathrm{P}_{\mathrm{ref}}$ was the median of the ambient power density over $2 \mathrm{~min}$ (without shielding) and $\mathrm{P}_{\mathrm{inv}}$ was the median of the measured power density with shielding material installed (over 2min).

$$
\mathrm{dB}=10 \log _{10}\left[\left(\mathrm{P}_{\mathrm{ref}}\left(\mathrm{W} / \mathrm{m}^{2}\right)\right) /\left(\mathrm{P}_{\mathrm{inv}}(\mathrm{W})\right)\right]
$$

The measured RF EMF mitigation materials under semicontrolled conditions included the following:

- graphite based and/or composite materials based on conductive paint used to cover walls,

- $\quad$ an iron wire netting with a loop size of $1.3 \times 2.6 \mathrm{~cm}$ (Fig. 4),

- an iron wire netting with a loop size of $12.5 \times 12.5 \mathrm{~cm}$,

- a foil paper,

- a metallized canvas used for curtains (Fig. 5),

- a frame of $45 \times 33 \mathrm{~cm}$ (three in a column with a total height of $1 \mathrm{~m}$ ) of conductive material (aluminum tape width of $25 \mathrm{~mm})$,

- metal bars with a gap of a) $10 \mathrm{~cm}$ and b) $20 \mathrm{~cm}$.

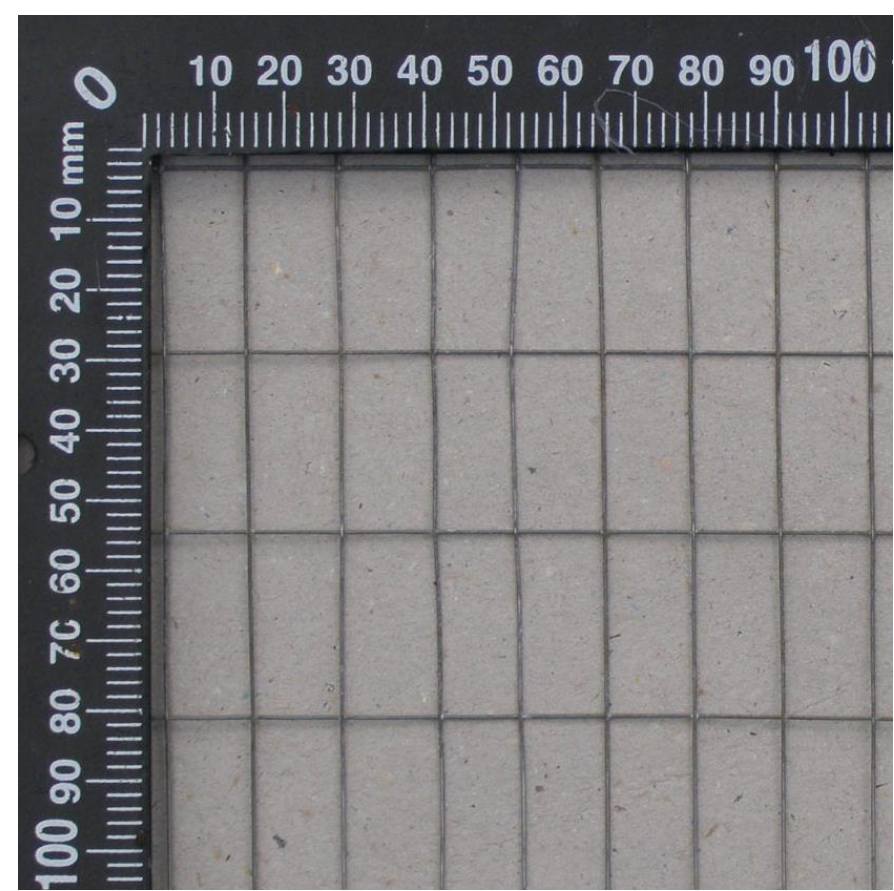

Fig. 4. Iron wire netting with a loop size of $13 \times 26 \mathrm{~mm}$.

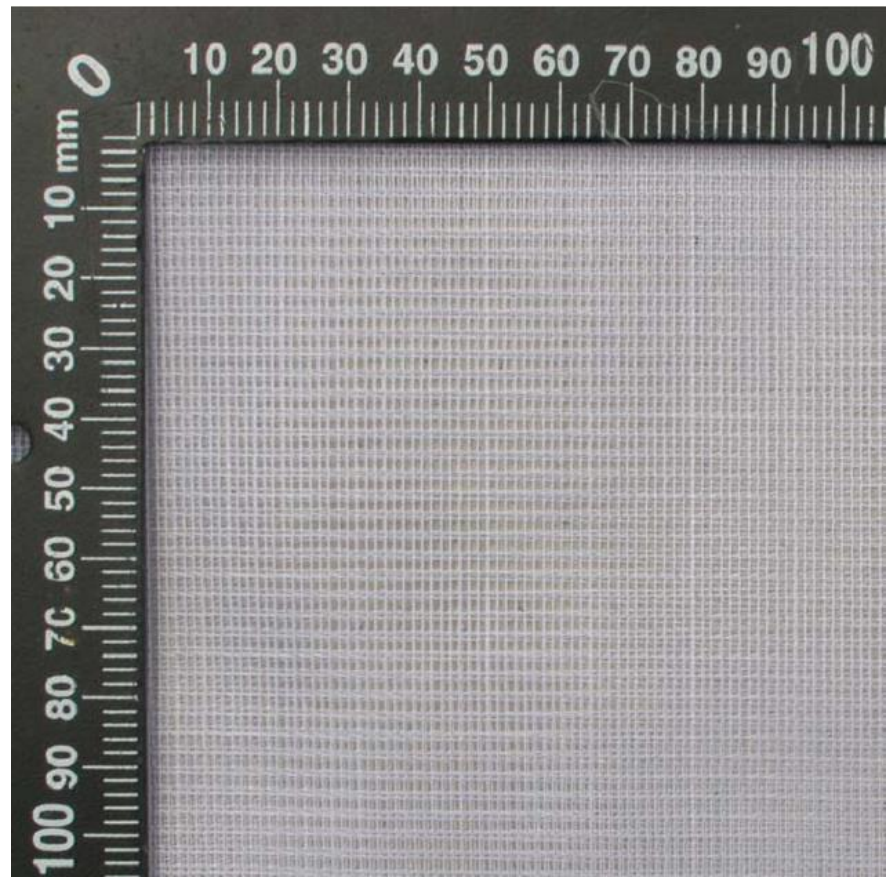

Fig. 5. Metallized canvas.

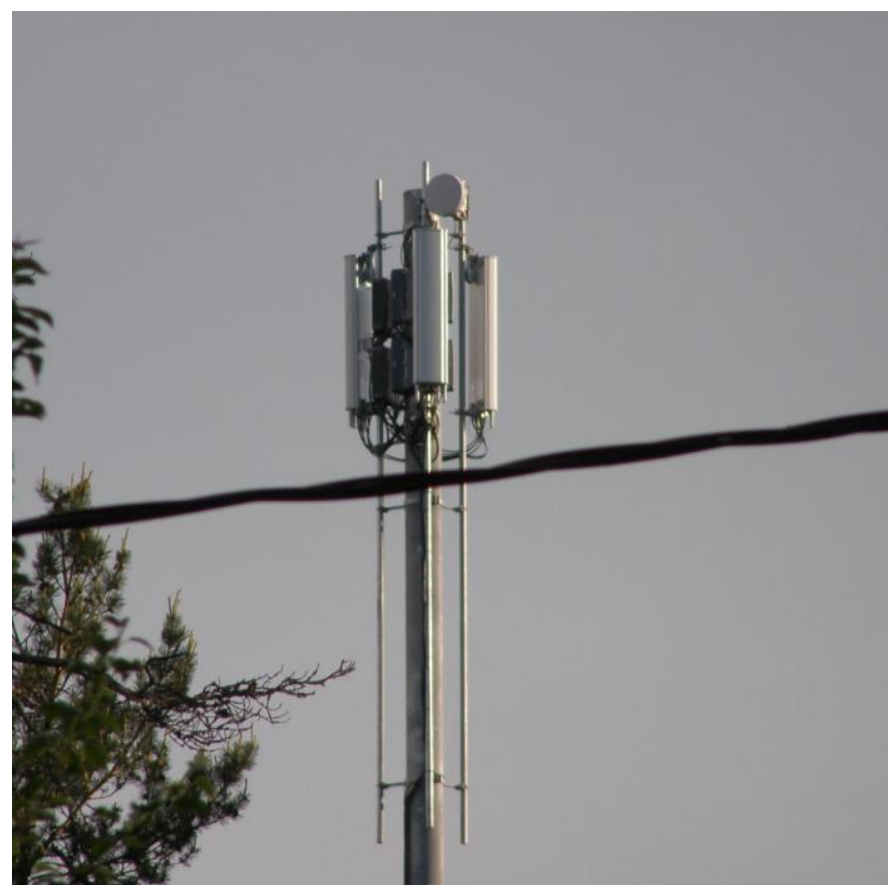

Fig. 6. The site for semi-controlled measurements was selected to be in a private residential area within $150 \mathrm{~m}$ from the mobile communication mast.

\section{B. Measurements before and after the Intervention Measures in the Actual Living and Working Environment}

The EMF was emitted by a mobile phone base station antenna and a Wi-Fi (Wireless Fidelity) router, both outside the apartment. The mobile base station was operating at 2110 $2170 \mathrm{GHz}$ frequency. The Wi-Fi technology operates at $2450 \mathrm{MHz}$ with 10-250 $\mathrm{Hz}$ pulses [30]. 
Three different mitigation scenarios were investigated:

1. A window with and without a shielding curtain (manufacturer claimed attenuation of $25 \mathrm{~dB}$ at $1 \mathrm{GHz}$ ). First, we opened the window and made measurement 'in-the-air' directly to the mobile base station. Thereafter we measured the power density level inside a house through a normal window. Finally, a metallized fabric curtain in front of a window was installed and its shielding efficiency at a distance of $20 \mathrm{~cm}$ was measured.

2. A second window with and without a shielding film (manufacturer claimed attenuation of $22 \mathrm{~dB}$, i.e., $99.37 \%$ at $1 \mathrm{GHz}$ ). First, we opened the window and made a measurement 'in-the-air' directly to the mobile base station. Thereafter we measured the power density level inside a house through a normal window. A special shielding film was attached to a window and its shielding efficiency at a distance of $20 \mathrm{~m}$ was measured before and after shielding.

3. An ordinary wooden ceiling and a shield-painted ceiling were compared. The paint used was a common brand RF shielding paint. A Wi-Fi router operated in the upper floor and measurements were done just beneath it, in the room below. The measurements were taken at a distance of $20 \mathrm{~cm}$ from the ceiling.

In all measurements both RMS (root mean square) and peak hold value were recorded.

\section{RESULTS}

Altogether 17 RF EMF mitigation scenarios were investigated and measured. Measurements were conducted in Tallinn (Estonia) and in Tampere (Finland).

\section{A. Measurements under Semi-controlled Conditions}

The measurement results revealed vast differences in the shielding effectiveness of the materials tested. The best shielding effectiveness was achieved by a two-layer metallized canvas used as curtains (Table I). Shielding of the same order of magnitude can also be achieved by foil paper and iron wire netting (small loop size of $13 \times 26 \mathrm{~mm}$ ). With iron wire netting tests were also done to cover up the entire measurement booth: covering four walls instead of one provided insignificant additional effect, whereas covering the roof of the booth reduced the RF power density inside the booth from $114 \mu \mathrm{W} / \mathrm{m}^{2}$ (only one side covered) to $43 \mu \mathrm{W} / \mathrm{m}^{2}$ (all sides plus top covered). This demonstrates that a significant part of the radiation was entering the booth vertically, due to possible reflections from neighboring houses. Whereas the metallized canvas had a loop size in the millimeter range, it was clear that the larger the loop size the less reduction in power intensity. This is illustrated by iron wire netting with a loop size of $125 \times 125 \mathrm{~mm}$, which provided no reduction in RF field levels. An iron wire netting with a loop size of $13 \times 26 \mathrm{~mm}$ proved to have a reduction factor with the best cost-benefit ratio. This relatively cheap netting came close to the metallized fabric's properties when being grounded. A foil paper could also be considered an economical alternative, although due to its radiopaque nature, it is not suited for usage where transparency (e.g., windows) is required.
Somewhat reduction in power density levels $(-6 \mathrm{~dB})$ can also be achieved by arranging metal bars (with $10 \mathrm{~cm}$ gaps) in front of the protected area and grounding them.

TABLE I

SHIELDING EFFECTIVENESS OF TESTED MATERIALS

\begin{tabular}{|l|c|c|}
\hline Tested material & $\begin{array}{c}\text { Median } \\
\left(\mu \mathrm{W} / \mathrm{m}^{2}\right)\end{array}$ & $\begin{array}{c}\text { Reductio } \\
\mathrm{n}(\mathrm{dB})\end{array}$ \\
\hline Iron wire netting (a13x26mm) & 114 & -9.9 \\
\hline Iron wire netting (a13x26mm) grounded & 87 & -10.4 \\
\hline Iron wire netting (a13x26mm) all sides & 97 & -10.6 \\
\hline Iron wire netting (a13x26mm) all sides and top & 43 & -14.1 \\
\hline Iron wire netting (a125x125mm) & 1310 & 0 \\
\hline Graphite paint & 1126 & -0.5 \\
\hline Foil paper & 68 & -12.7 \\
\hline Metallized canvas (1layer) & 47 & -13.7 \\
\hline Metallized canvas (2layers) & 40 & -14.4 \\
\hline Iron bars (10cm gap), grounded & 241 & -5.9 \\
\hline Iron bars (20cm gap), grounded & 538 & -2.5 \\
\hline Iron bar (one in front of the meter), grounded & 630 & -1.8 \\
\hline Metallic frame 45x33(100)mm & 949 & 0.3 \\
\hline
\end{tabular}

The spectral analysis of the HF radiation source revealed the most strongest signals to be allocated to the wireless data transmissions (the Internet) and GSM mobile telephony (Fig. 7). Time series analysis of the measured spectrum showed no remarkable change in the composition of various frequencies throughout the measurements. The mitigation activities and materials undertaken were proportionally reducing all the signals in the range.

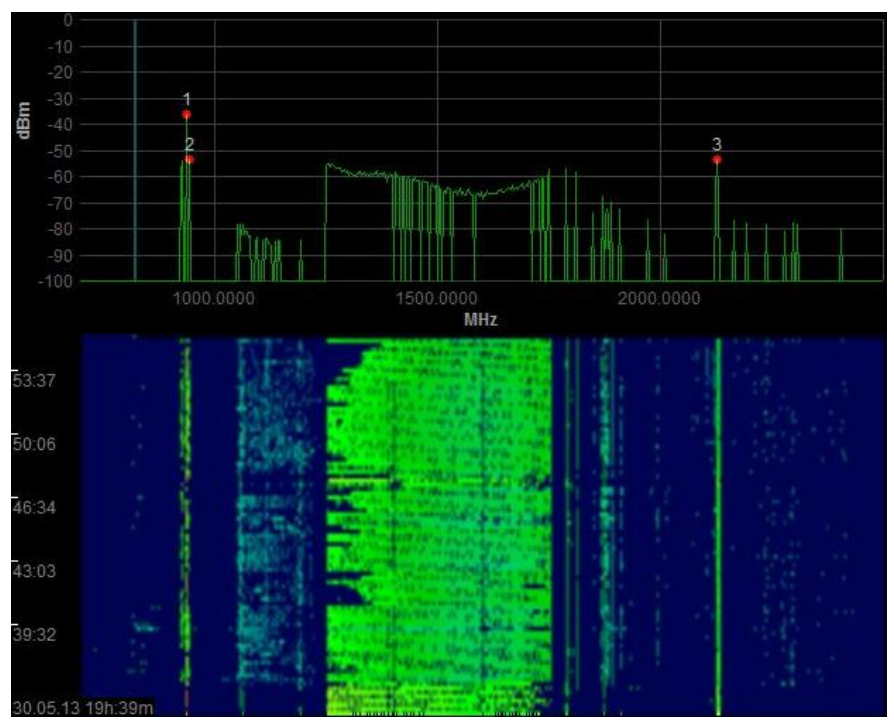

Fig. 7. Spectral distribution of the measured signals (upper) and their dynamic in time (lower) of the semi-controlled measurement site; from 700 to $2500 \mathrm{MHz}$ with $1 \mathrm{~s}$ sample time and bandwidth resolution of $3 \mathrm{MHz}$. Three strongest frequencies are marked as 1,2 and 3

The average power density level at the semi-controlled measurement location was approximately $1 \mathrm{~mW} / \mathrm{m}^{2}$. Figures 8 to 14 picture some of the mitigation materials that were used in this study. 


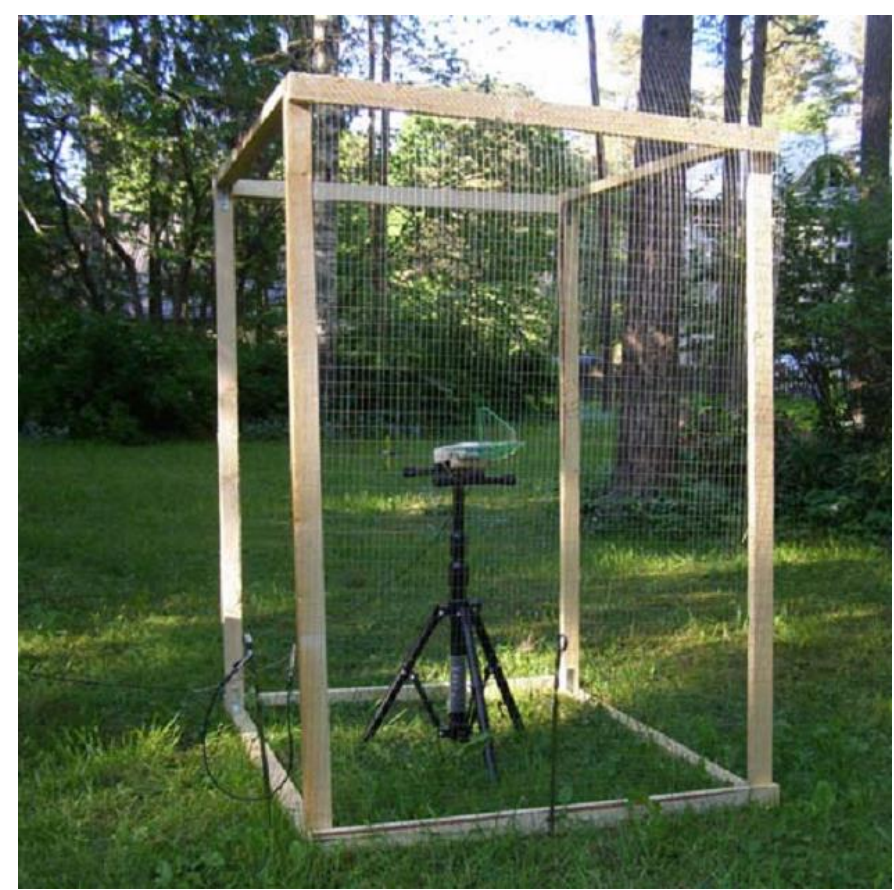

Fig. 8. Testing of iron wire netting $(\propto 13 \times 26 \mathrm{~mm})$.

Spatial measurements conducted behind the iron wire netting revealed the RF field to be mitigated quite inhomogeneously both in horizontal (figure 9) and vertical plane (Fig. 10).

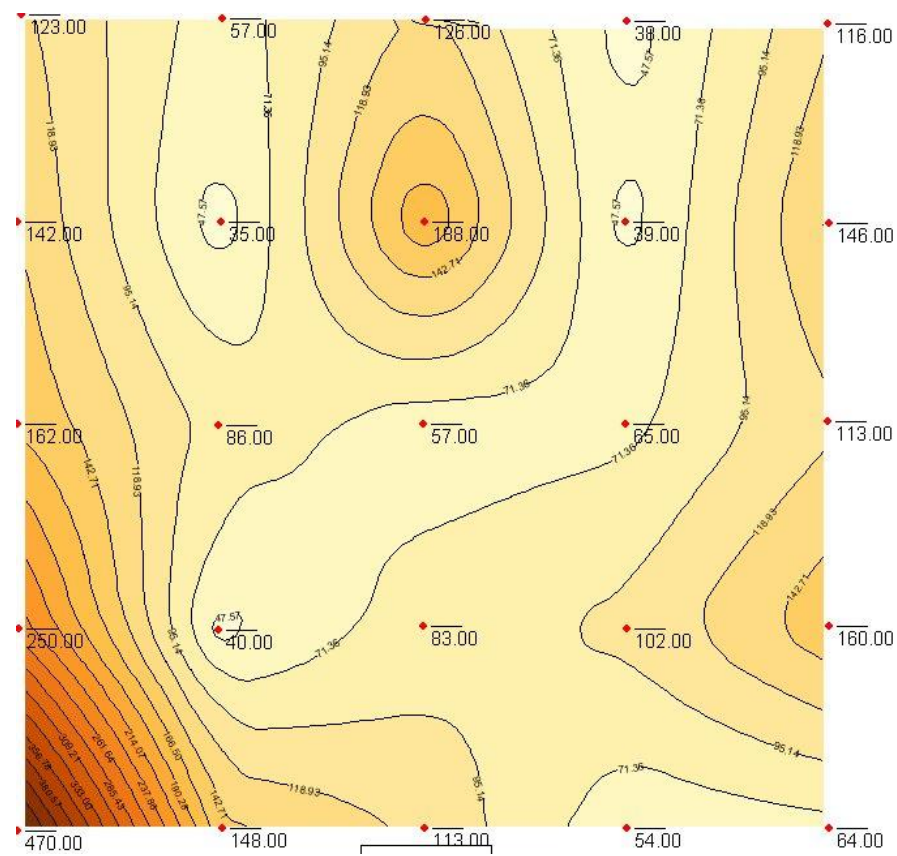

Fig. 9. Horizontal plane spatial measurements in the test booth shielded by iron wire netting $(13 \times 26 \mathrm{~mm})$; netting in the upper part; RF EMFs coming from the upper side; measurements $0.7 \mathrm{~m}$ from the ground; units in $\mu \mathrm{W} / \mathrm{m}^{2}$.

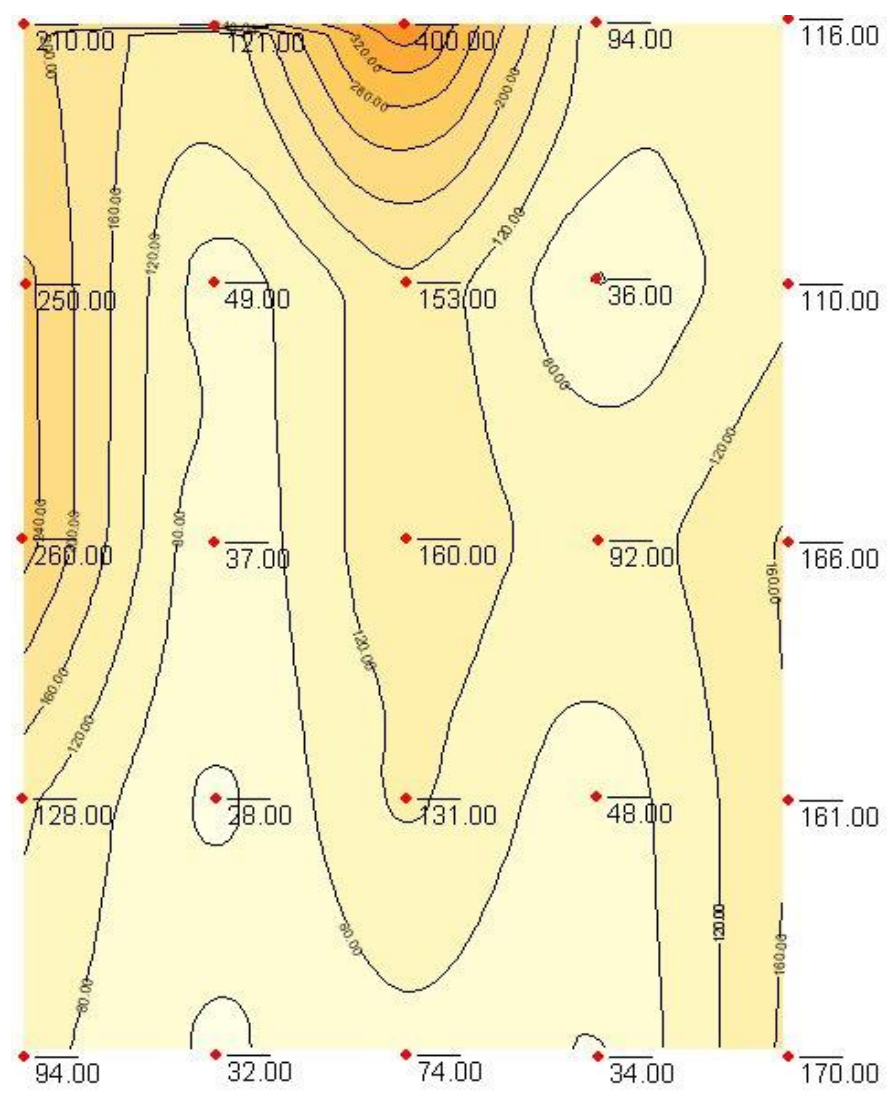

Fig. 10. Vertical plain spatial measurements in the test booth shielded by iron wire netting $(\alpha 13 \times 26 \mathrm{~mm})$; measurement taken $15 \mathrm{~cm}$ behind the netting; units in $\mu \mathrm{W} / \mathrm{m}^{2}$.

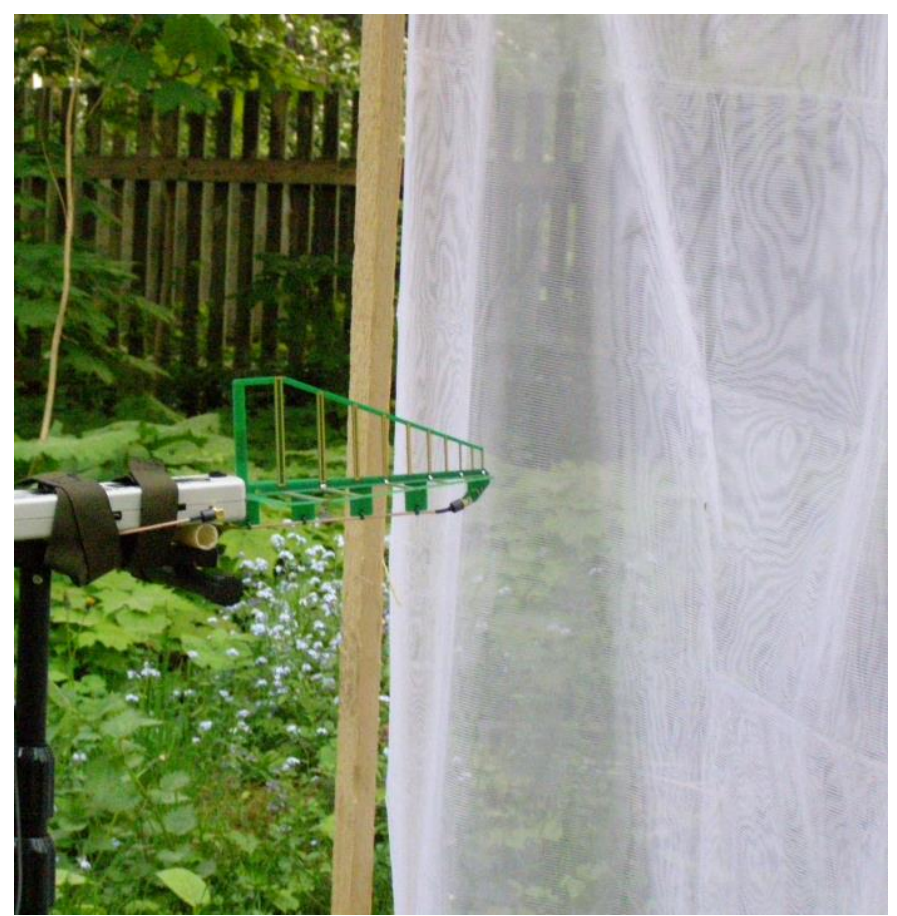

Fig. 11. Testing the shielding effectiveness of a metallized fabric used for curtains. 


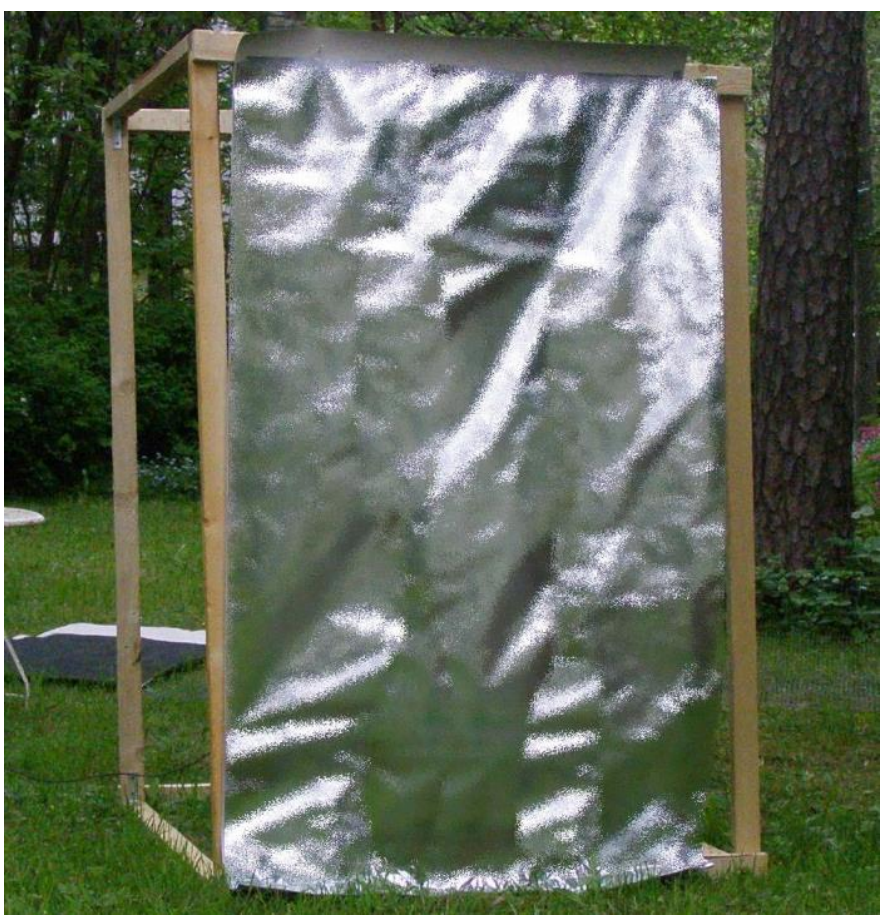

Fig. 12. Testing the shielding effectiveness of a cooking folium.

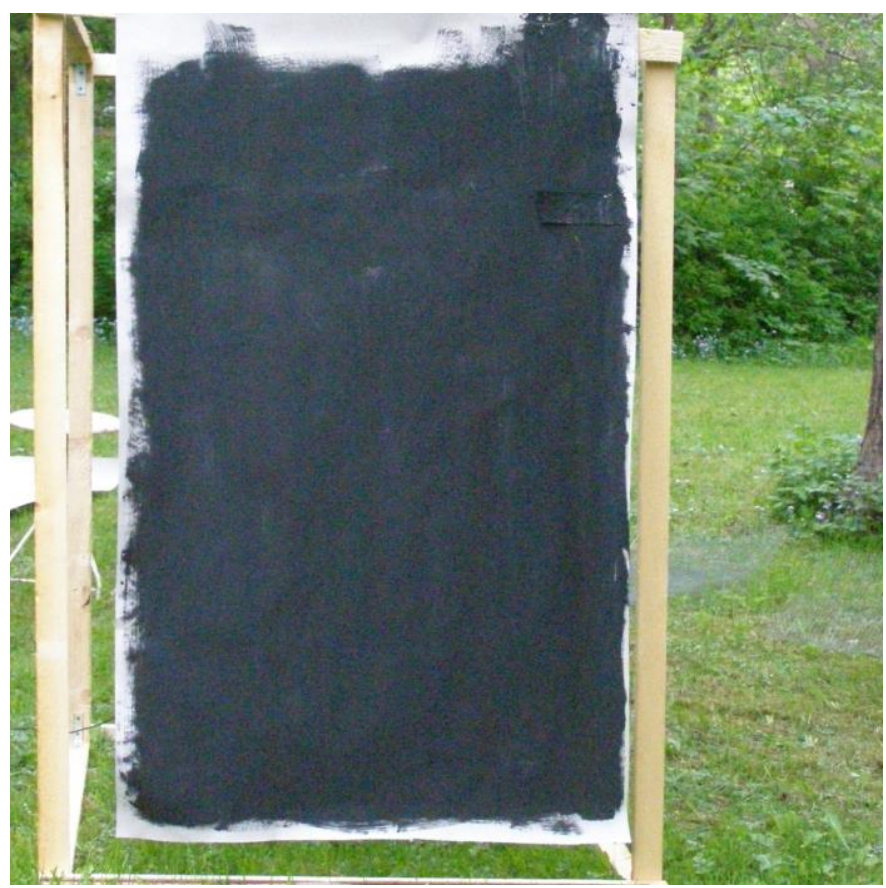

Fig. 13. Testing the shielding effectiveness of graphite based paint.

A "shielding" material with a metal frame was prepared to disprove a popular misconception that a metallic contour of arbitrary size is able to screen out the RF EMFs (Fig. 14). Although it is obvious that microwaves are small enough to pass through such obstacles, this test done with an actual setting even showed that a metallic contour may start to act as an antenna and even slightly to increase the power density levels.

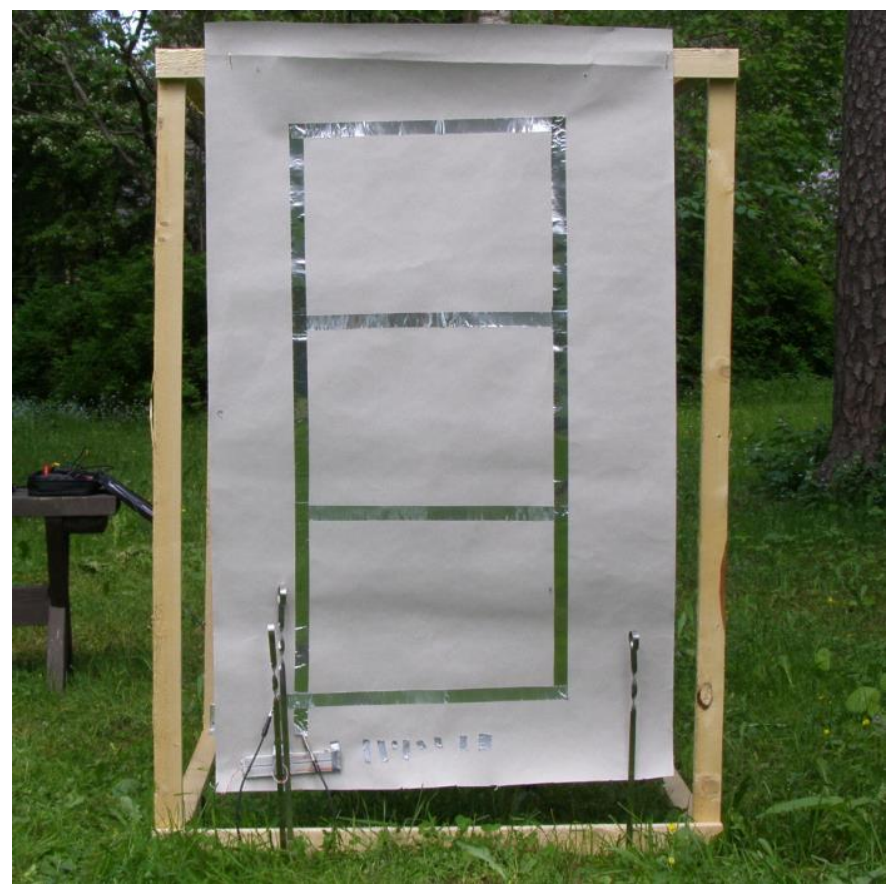

Fig. 14. Testing the shielding effectiveness of metallic frame $45 \times 33(100) \mathrm{mm}$ (aluminium tape width $25 \mathrm{~mm}$ ), grounded .

\section{B. Measurements before and after the Intervention Measures in} the Actual Living and Working Environments

A special shielding film was attached to a window of a house. The source of the RF EMFs was a mobile base station nearby (transmitting also 3G signals). Before the intervention the power density level was $19.9 \mu \mathrm{W} / \mathrm{m}^{2}$ (peak value), measured at a distance of $20 \mathrm{~cm}$ from the window. After shielding the power density level dropped to $0.87 \mu \mathrm{W} / \mathrm{m}^{2}$ (peak value), measured at a distance of $20 \mathrm{~cm}$ from the window. The experiment was conducted in a rather lowradiation environment. The effectiveness of the shielding film (metallized plastic cover) also depends on the window frame and its material. Best effect is achieved together with aluminum or similar metal window frames.

The second intervention experiment compared two adjacent rooms, with identical construction materials (ceiling made of chipboard), but with one having a shielded ceiling. To test the effectiveness, a RF EMF irradiator (wireless network router) was placed right above the ceiling. Another room's ceiling was shielded with a special EMF paint containing metallic fibers. Readings were taken in the center of the room, $20 \mathrm{~cm}$ from the ceiling. The results showed that the shielding reduced the RF EMF levels (peak values) tenfold (table II). The reduction of RF radiation was more than tenfold. However, in the test set-up there was only one layer of paint. To radically reduce the exposure levels, the surface needs to be painted several times. 
TABLE II

THE SHIELDING EFFICIENCY OF A METALLIZED FABRIC

\begin{tabular}{|l|c|c|c|}
\hline Location & $\begin{array}{c}\mathrm{RMS} \\
\left(\mu \mathrm{W} / \mathrm{m}^{2}\right)\end{array}$ & $\begin{array}{c}\text { Peak } \\
\left(\mu \mathrm{W} / \mathrm{m}^{2}\right)\end{array}$ & $\begin{array}{c}\text { Reduction, } \\
\text { peak }(\mathrm{dB})\end{array}$ \\
\hline Unshielded room & 58 & 7170 & 0 \\
\hline Shielded room & 5 & 550 & 11.2 \\
\hline
\end{tabular}

The third in-house experiment was done with a special curtain made of metallized fabric. Table III presents the results in three modes: with an open window; with a closed window and with a closed window and a curtain in front of the window. The curtain reduced peak values approximately hundredfold. The reduction of such great magnitude was achieved also due to the brick walls that disallowed any radiation to enter the room through walls or construction elements.

\section{TABLE III}

THE SHIELDING EFFICIENCY OF A METALLIZED FABRIC

\begin{tabular}{|l|c|c|c|}
\hline Measurement condition & $\begin{array}{c}\mathrm{RMS} \\
\left(\mu \mathrm{W} / \mathrm{m}^{2}\right)\end{array}$ & $\begin{array}{c}\text { Peak } \\
\left(\mu \mathrm{W} / \mathrm{m}^{2}\right)\end{array}$ & $\begin{array}{c}\text { Reduction, } \\
\text { peak }(\mathrm{dB})\end{array}$ \\
\hline $\begin{array}{l}\text { Window open (direct contact } \\
\text { with inbound RF EMFs) }\end{array}$ & 55 & 176 & 0 \\
\hline $\begin{array}{l}\text { Window closed (inbound RF } \\
\text { EMFs shielded by a triple glass) }\end{array}$ & 48 & 147 & 0.8 \\
\hline $\begin{array}{l}\text { Metallized fabric (inbound RF } \\
\text { EMFs shielded by a triple glass } \\
\text { and a special curtain) }\end{array}$ & 0,89 & 1,65 & 20.3 \\
\hline
\end{tabular}

\section{CONCLUSIONS AND DISCUSSION}

This study tested various RF EMF mitigation materials. The measurements show the best results to be attained by the material that also is the most expensive - metallized canvas (curtain). The shielding effect is greatly dependent on the fabric's weft opening size - the smaller the weft the better the reduction factor. Similar conclusions were drawn also by Roh et al [1]. Additionally, the electric conductivity of the material plays its role - the less conductivity, the more energy is absorbed by the material. The lower the material's conductivity, the higher the temperature rises due to microwave absorption compared to the materials with high conductivity [31]. Considering the results from measuring the shielding effect of iron wire netting (a highly conductive material), additionally performed spatial measurements showed an inhomogeneous distribution of field power density behind the netting. This is possible due to the reflective properties of the material, since the higher conductivity, the more reflective the material tends to be.

When Ro et al. (2008) tested metal nets, they discovered that the shielding effectiveness increased with metal content, but different frequency dependence related to the aspect ratio of metal grid structure was discovered. It was shown that the EMSE of the metal composite fabrics could be tailored by modifying the metal grid size and geometry [1].
While implementing shielding solutions, it must be noted that with metal-containing materials a proper earthing is often essential, since thunderstorms and sudden power surges in the electrical network may be risky close to metals. If the metal shielding is ungrounded, it may become an additional antenna for the RF EMFs. Therefore, grounding metal objects is relevant both from the shielding point of view and from electrical safety (avoiding electrical shocks) point of view.

This study also concluded that in order to achieve a good reduction factor, the mitigation must be absolute. Measurements done in semi-controlled conditions revealed that when the experimental booth was covered from all sides and top, even the slightest gaps in between the iron wire netting would allow microwave to leak in and to raise the levels significantly. When all gaps were closed, the mitigation reduced from about 70 to $40 \mu \mathrm{W} / \mathrm{m}^{2}$.

Mitigation improvements tend to become even more costly when considering aesthetic aspects of different materials. Whereas walls can be covered with any of the solutions tested in this paper, iron bars or iron wire netting on the windows would not be a suitable choice. Moreover, windows are the main opening where the RF EMFs enter any room; therefore, most attention should be paid there. As with many other environmental improvement investments the owner is faced with an optimization task of finding the best cost-benefit ratio.

\section{REFERENCES}

[1] J.-S. Roh, Y.-S. Chi, T. J. Kang and S. Nam, "Electromagnetic Shielding Effectiveness of Multifunctional Metal Composite Fabrics", Textile Research Journal, vol. 78(9), 2008, pp. 825-835. http://dx.doi.org/10.1177/0040517507089748

[2] H. Aniołczyk and J. Koprowska, "Occupational and public EMF exposure - textiles shields as a modern approach for protection", 11th International Congress of the International Radiation Protection Association, Madrid, Spain, 23-28 May 2004, [CD-ROM] Available: http://irpa11.irpa.net/pdfs/8d2.pdf [Accessed: June 1, 2013].

[3] K.H. Mild, T. Alanko, G. Decat, R. Falsaperia, K. Gryz, M. Hietanen, J. Karpowicz, P. Rossi, M. Sandström, "Exposure of workers to electromagnetic fields. A review of open questions on exposure assessment techniques", International Journal of Occupational Safety and Ergonomics (JOSE), vol. 15 (1), 2009, pp. 3-33.

[4] International Commission on Non-Ionizing Radiation Protection, (ICNIRP) Guidelines for limiting exposure to time-varying electric, magnetic and electromagnetic fields (up to $300 \mathrm{GHz}$ ), Health Physics, vol. 74(4), 1998, üü. 494-522.

[5] Institute of Electrical and Electronics Engineers (IEEE), IEEE standard for safety levels with respect to human exposure to radio frequency electromagnetic fields, 3kHZ to $300 \mathrm{GHz}$ (Standard No. C95.1:2005), New York, USA, 2005.

[6] Directive 2004/40/EC of the European Parliament and the Council of 29 April 2004 on the minimum health and safety requirements regarding the exposure of workers to the risks arising from physical agents (electromagnetic fields) (18th individual Directive within the meaning of Article 16(1) of Directive 89/391/EEC) Official Journal of the European Union L 159 of 30 April 2004.

[7] Council recommendation of 12 July 1999 on the limitation of exposure of the general public to electromagnetic fields $(0 \mathrm{~Hz}$ to $300 \mathrm{GHz})$ (1999/519/EC) Official Journal of the European Communities, L 199/59, 30. 7.1999.

[8] B. Hocking and K. H. Mild, "Guidance note: Risk management of workers with medical electronic devices and metallic implants in electromagnetic fields", International Journal of Occupational Safety and Ergonomics (JOSE), vol. 14(2), 2008, pp. 217-222. 
[9] X. Yu, Z. Shen, C. Cai, "Millimeter wave electromagnetic interference shielding by coating expanded polystyrene particles with a copper film using magnetron sputtering", Vacuum, vol. 83, 2009, pp. 1438-1441. http://dx.doi.org/10.1016/j.vacuum.2009.05.021

[10] K.B. Cheng, S. Ramakrishna, K.C. Lee, "Electromagnetic shielding effectiveness of copper/glass fiber knitted fabric reinforced polypropylene composites", Composites, Part A: applied science and manufacturing, 2000, pp. 1039-1045. http://dx.doi.org/10.1016/S1359-835X(00)00071-3

[11] H.-C. Chen, K.-C. Lee, J.-H. Lin, „Electromagnetic and electrostatic shielding properties of co-weaving-knitting fabrics reinforced composites", Composites, Part A: Applied science and manufacturing, vol. 35, 2004, pp. 1249-1256. http://dx.doi.org/10.1016/j.compositesa.2004.04.006

[12] Z. Dou, G. Wu, X. Huang, D. Sun, L. Jiang, “,Electromagnetic shielding effectiveness of aluminium alloy-fly ash composites", Composites, Part A: Applied science and manufacturing, vol. 38, 2007, pp. 186-191. http://dx.doi.org/10.1016/j.compositesa.2006.01.015

[13] H.-C. Chen, K.-C. Lee, J.-H. Lin, M. Koch „, Fabrication of conductive woven fabric and analysis of electromagnetic shielding via measurement and empirical equation", Journal of materials processing technology, vol. 184,2007 , pp. 124-130. http://dx.doi.org/10.1016/j.jmatprotec.2006.11.030

[14] Y. Li , C. Chen, S. Zhang, Y. Ni, J. Huang, "Electrical conductivity and electromagnetic interference shielding characteristics of multiwalled carbon nanotube filled polyacrylate composite films", Applied Surface Science, vol. 254, 2008, pp. 5766-5771. http://dx.doi.org/10.1016/j.apsusc.2008.03.077

[15] K.-Y. Park, S.-E. Lee, C.-G. Kim, J.-H. Han, ” Application of MWNTadded glass fabric/epoxy composites to electromagnetic wave shielding enclosures", Composite Structures, vol. 81, 2007, pp. 401-406. http://dx.doi.org/10.1016/j.compstruct.2006.08.029

[16] S. W. Kim, Y. W. Yoonb, S.J. Leea, G. Y. Kimc, Y. B. Kimc, Y. Y Chunb, K. S. Leeb, "Electromagnetic shielding properties of sof magnetic powder-polymer composite films for the application to suppress noise in the radio frequency range", Journal of Magnetism and Magnetic Materials, vol. 316, 2007, pp. 472-474 http://dx.doi.org/10.1016/j.jmmm.2007.03.133

[17] T.-W. Shyr, J.-W. Shie, "Electromagnetic shielding mechanisms using soft magnetic stainless steel fiber enabledpolyestertextiles", Journal of Magnetism and Magnetic Materials, vol. 324, 2012, pp. 4127-4132. http://dx.doi.org/10.1016/j.jmmm.2012.07.037

[18] B.R. Kim, H.K. Lee, E. Kimb, S.-H. Lee, "Intrinsic electromagnetic radiation shielding/absorbing characteristics of polyaniline-coated transparent thin films", Synthetic Metals, vol. 160, 2010, pp. 1838-1842. http://dx.doi.org/10.1016/j.synthmet.2010.06.027

[19] H. Guan, S. Liu, Y. Duan, J. Cheng, " Cement based electromagnetic shielding and absorbing building materials", Cement \& Concrete Composites, vol. 28, 2006, pp. 468-474.

http://dx.doi.org/10.1016/j.cemconcomp.2005.12.004

[20] C. J. von Klemperer, D. Maharaj, „Composite electromagnetic interference shielding materials for aerospace applications", Composite Structures 91, 2009, pp. 467-472. http://dx.doi.org/10.1016/j.compstruct.2009.04.013

[21] EP- European Parliament Committee on the Environment, Public Health and Food Safety. Report on health concerns associated with electromagnetic fields lectromagnetic fields (2008/2211(INI)). 2009.
[22] CE-Council of Europe Parliamentary Assembly, Committee on the Environment, Agriculture and Local and Regional Affairs. The potential dangers of electromagnetic fields and their effect on the environment. 2011. http://assembly.coe.int/main.asp?link=/documents/workingdocs/ doc11/edoc12608.htm.

[23] IARC (2013). WHO International Association on Research on Cancer. Non-ionizing Radiation, Part 2: Radiofrequency Electromagnetic Fields, volume 102, iarc monographs on the evaluati on of carcinogenic risks to humans.

[24] EEA (2013), European Environmental Agency. Late lessons from early warnings: science, precaution, innovation. EEA Report No 1/2013 [Online]. Available: http://www.eea.europa.eu/publications/late-lessons-2 [Accessed 3rd June 2013].

[25] BioInitiative Working Group, Bioinitiative report: A Rationale for a Biologically Based Public Exposure Standard for Electromagnetic Fields, 2007

[26] BioInitiative Working Group, Cindy Sage and David O. Carpenter, Editors. BioInitiative Report: A Rationale for a Biologically-based Public Exposure Standard for Electromagnetic Radiation at www.bioinitiative.org, December 31, 2012.

[27] SCENIHR-Scientific Committee on Emerging and Newly Identified Health Risks. Health Effects of Exposure to EMF. European Commission Directorate-General for Health \& Consumers. 2009.

[28] EHFHRAN - European Health Risk Assessment Network on Electromgnetic Fields Exposure. 2010. Risk Analysis of human exposure to electromagnetic fields, report D2 of EHFRAN project [Online]. http://efhran.polimi.it/docs/EFHRAN_D2_final.pdf

[29] T. Koppel, T. Tasa, P. Tint, "Electromagnetic fields in contemporary office workplaces", Agronomy Research, vol. 11(2), 2013, pp. 421 - 434

[30] Federal Office for the Environment (FOEN), "Electrosmog in the environment", Report DIV-5801-E, 2012. [Online]. Available: http://www.bafu.admin.ch/publikationen/publikation/00686/index.html? ang=en [Accessed: June 1, 2013].

[31] E. Hakansson, A. Amiet, S. Nahavandi, A. Kaynak, "Electromagnetic interference shielding and radiation absorption in thin polypyrrole films", European Polymer Journal, vol. 43, 2007, pp. 205-213. http://dx.doi.org/10.1016/j.eurpolymj.2006.10.001

Tarmo Koppel is a Researcher and lecturer in the field of electromagnetic fields and their induced health effects. He is conducting his doctoral research at Tallinn University of Technology. The author has earned his BA and MA both at Tallinn University of Technology and currently he has moved into the most active stage of conducting his doctoral research. The author is also involved in studying other environmental aspects such as lighting. E-mail: tarmo.koppel@ ttu.ee| http://www.ttu.ee/tarmo-koppel/en

Mikko Ahonen obtained his Doctoral Degree in Information Systems in 2011. His research interest is focused on bioelectromagnetics and mobile learning. Currently his research group studies environmental factors related to autism and ADHD at the University of Tampere, Finland. He has also worked in the telecom business and is a partner of an EMF risk-management company.

E-mail: mikko.p.ahonen@ uta.fi |http://www.uta.fi/ kamiah 